\title{
Optimization of Earth Air Tube Heat Exchanger for Cooling Application Using Taguchi Technique
}

\author{
Saif Nawaz Ahmad*, Om Prakash \\ Department of Mechanical Engineering, National Institute of Technology (NITP), Patna 800005, India
}

Corresponding Author Email: saifa.phd17.me@ nitp.ac.in

https://doi.org/10.18280/ijht.380411

Received: 14 May 2019

Accepted: 20 November 2020

\section{Keywords:}

Taguchi, analysis of variance (ANOVA), earth air tube heat exchanger, optimisation, ground heat exchanger length, overall heat transfer coefficient

\begin{abstract}
Earth air tube heat exchanger (EATHE) is one of the passive technologies which utilize the earth stored heat (renewable energy) for heating/cooling the buildings. EATHE releases heat to earth for cooling space in summer, making the earth a heat sink and extracts earthstored energy for heating space in winter and makes the earth a heat source. This paper optimizes the Length of the ground heat exchanger and overall heat transfer coefficient of earth air heat exchanger using the Taguchi technique for cooling application. For this purpose, we select six factors such as installation depth of Pipe (A), Pipe's inner diameter (B), Thermal conductivity of pipe material (C), Inlet air temperature (D), Outlet air temperature $(\mathrm{E})$, Inlet air velocity $(\mathrm{F})$. All these factors are taken at three levels, and we select an $\mathrm{L}_{27}$ orthogonal array for experimental runs. The ground heat exchanger's Length and the overall heat transfer coefficient were then calculated for each experimental run. In the Taguchi method, we find the signal to noise ratio for an optimal combination of all six factors and ANOVA to find the order of influencing parameters and their percentage contributions for both the objective parameters. According to our results, the best combination for all the six factors for ground heat exchanger length and overall heat transfer coefficient were A1B1C3D1E3F1 and A2B3C2D3E1F3, respectively. The highest and lowest influencing factors for ground heat exchanger length were the pipe's inner diameter and the pipe's installation depth with their contribution factors of 69.12 and $0.32 \%$, respectively. In contrast, the highest and lowest influencing factors for the overall heat transfer coefficient were the pipe's inner diameter and thermal conductivity of pipe material with their contribution factors of 75.97 and $0 \%$, respectively. Hence the order of influence of all the six factors for both the objective parameters was BEFDCA.
\end{abstract}

\section{INTRODUCTION}

Space conditioning for residential and industrial purposes is a special need now a days, and this demand increases day by day. As we know that the expenditure of energy on space heating and cooling is about one-fourth of the world's total consumed energy. Most of the conventional conditioning system consumed electrical energy produced by burning fossil fuels in the power plants and termed as high-grade energy. Since fossil fuel burning in power plants emits harmful gases and causes global warming, that is the significant challenge for a sustainable environment. These increased amounts of energy consumption and adverse effects on the environment for space heating or cooling forced the researchers to search the different types of conditioning systems that consume less energy or work and become environment friendly. Hence various passive technology and renewable energy sources are the best alternatives for conditioning the space and meeting our demands. The most popular passive technology for space conditioning is the Earth air tube heat exchanger, which utilizes geothermal energy. Solar energy, which is stored in the ground, is termed as geothermal energy. Hence geothermal energy sources are renewable and sustainable sources that can be employed to heat or cool the space using Earth air tube heat exchanger. The earth has a relatively constant temperature at a certain depth and is lower than the ambient temperature in summer and vice versa in the winter season. This earth property is beneficial in installing and implementing Earth's air tube heat exchanger (EATHE), making earth as a source in winter for heating and sink in summer for cooling.

Earth air tube heat exchangers are mainly affected by the soil temperature at a certain depth. As the soil temperature remains constant at a given depth, we study the amplitude of soil temperature as a function of depth only. Therefore, we only consider the soil's heat transfer process of a nearby pipe's close vicinity than the overall soil heat transfer. In the surface zone, the soil temperature is sensitive due to weather conditions, while in the shallow zone, the ground temperature is mainly affected by the cyclic climatic condition. So at the end of this zone, the temperature of the ground remains almost constant. Since the deep zone is mainly affected by geothermal gradient such as porosity, conductivity, etc., the EATHE system is generally established at the end of the shallow zone [1]. The variation of temperature with depth after $2 \mathrm{~m}$ is minimal within a range of $1^{\circ} \mathrm{C}$ [2]. The soil containing high thermal conductivity, high density, and high heat capacity is best suited for applying EATHE [3]. In an EATHE system, the pipes of the designed dimension and materials are covered in the earth at a given fixed depth. The soil releases the thermal energy to air that flowing inside a pipe in winter season for space heating when the outdoor temperature is lesser than the underground temperature and, in this way, earth work as a 
source, while in summer season for space cooling, the soil absorbs thermal energy from the air through pipe whenever the outdoor ambient temperature is greater than the underground temperature, and hence earth works as a sink.

Thus, heat is moved to or from the bounding soil by pipe and flowing air through conduction and convection, respectively [4]. Fans, blowers, or any passive system are attached with EATHE to create a pressure difference by which air will flow continuously within the system. Generally, there are two major types of EATHE: open and closed, as shown in Figure 1. In an open-loop system, as shown in Figure (1a), the outdoor surrounding air directly flows in the buried ground heat exchanger for either pre-cooling or preheating of air. In a closed-loop ground heat exchanger system, as shown in Figure (1b), the heat transfer fluid (air) is re-circulated from the building to the heat exchanger releasing heat to or absorbing heat from the underground soil. The ground heat exchanger is arranged vertically or horizontally, but the vertical mode is more expensive than horizontal. There is an advantage of closed-loop on open-loop that the closed-loop is more conducive, and the problem of humidity is reduced drastically. A numerical calculation has been done to get the optimum value of dimensions of the tunnel and flow velocity of air inside the tunnel to extract the room's maximum heat at different values of required load and environmental conditions [5]. Spengler and Stombaugh [6] simulate the thermal performance based on a finite difference technique and optimizes the Length of the tube and flow rate inside the tube. Hence, they find the optimum combinations of tube length, number of tubes for different tube sizes for winter conditions using economic analysis. Agrawal et al. [7] proposed a methodology to optimize the earth air heat exchanger's operating parameters that affect the heat transfer rate and temperature drop for cooling application. They use the Taguchi method and ANOVA analysis to get the maximum drop in temperature and maximum heat transfer rate. They show the preferable combination of all parameters at four levels using the Taguchi method. They also produce the most influencing parameters for both the maximum temperature drop and heat transfer rate by finding respective contribution factors in ANOVA analysis.

Sivasakthivel et al. [8] and Pandey et al. [9] optimizes the Ground source heat pump system's various heating and cooling modes using the Taguchi technique and utility concept. Verma and Murugesan [10] analyzed the performance of solar assisted ground source heat pump system using the Taguchi technique and utility concept for heating application. They optimized the various designed parameters to obtain optimum ground heat exchanger length and solar collector area with optimum COP for space heating. Based on Taguchi's results, the specific heat of liquid in the ground heat exchanger is an insignificant factor. Similarly, for the solar collector area, the inner diameter of the solar collector pipe is insignificant.

Baglivo et al. [11] optimized horizontal air-ground heat exchanger with a residential building by evaluating the operative air temperature. According to their result, the favorable operative air temperature exists with a value of lower ground conductivity. Their results also suggest that the systems can reduce the building's temperature with a high mass flow rate of air. Kumar et al. [12] optimized the different earth air heat exchanger input variables using an intelligent design tool. They developed two models named deterministic and intelligent for evaluating the cooling or heating potential of the system. Carlucci et al. [13] installed an experimental setup of the EATHE system in a rural area. They emphasize the monitoring system through which the various information would be collected, and they also focus on their study regarding the selection of the type of soil, materials, layout, and sizing of the system. Kaushal et al. [14] optimized the hybrid earth air heat exchanger's process parameters by response surface methodology and investigated its thermal performance. The adequacy of the model has been checked using the sequential f-test and ANOVA technique. They investigate the performance of the hybrid EATHE system under five independent variables and two output responses. Their results show that the f-value of the proposed model for hybrid earth air heat exchanger and earth air heat exchanger are 791.848 and 35.420, respectively, and suggest that the presented models are significant. Tiwari et al. [15] designed an earth air heat exchanger for a given dimension of a room by optimizing the various variables such as Length of pipe, buried depth of pipe, pipe diameter, and the number of air changes. Their optimized result shows that the outlet air temperature in the summer season decreased by $5-6^{\circ} \mathrm{C}$. For this decrement in outlet temperature, the diameter and Length were optimized as $0.1 \mathrm{~m}$ and $21 \mathrm{~m}$, respectively. Diaz et al. [16] optimize the earth air heat exchanger's power consumption using a fuzzy logic controller. Their results suggest that the power consumption may be reduced when a fuzzy logic controller is used instead of an On-Off controller.

In the summer season for cooling purposes, various parameters would be optimized for the effective working of EATHE. In all these parameters, the tube's length and overall heat transfer coefficient are the key parameters. Hence, a methodology must be developed to surge these two fundamental parameters to achieve the given temperature drop, the pipe's diameter, and fluid flow properties. The fundamental goal of this paper is to optimized these two key parameters using the Taguchi method.

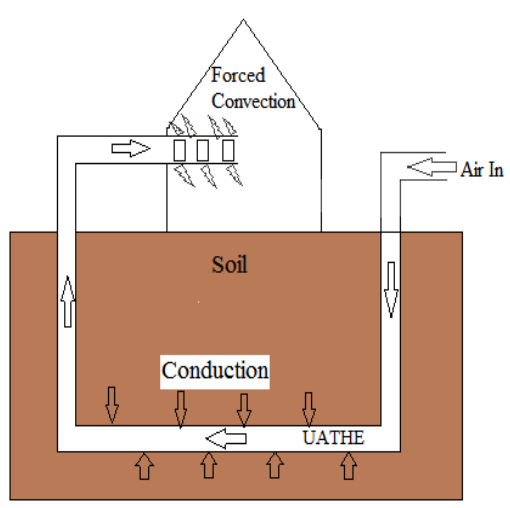

(a)

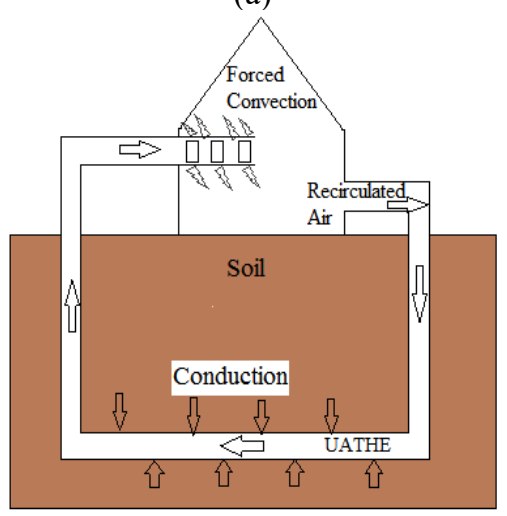

(b)

Figure 1. (a) open-loop EATHE (b) closed-loop EATHE 


\section{THERMAL MODELLING OF EATHE}

There are generally two modes of heat transfer in the EATHE system; one is convection, and the other is conduction. The working fluid (air) flows inside the buried pipe that transfers the heat to the soil bounded the pipe for cooling applications. Hence, heat transfer from flowing air to the tube's inner surface is taken place due to the convection mode of heat transfer. In contrast, transfer of heat from the inner surface to the tube's outer surface occurs by conduction mode of heat transfer, and lastly, the heat transfer from the tube's outer surface to bounded soil is taken place by the conduction mode of heat transfer. So, in this system, the number of heat transfer processes is three, while the number of heat transfer modes is two. Hence the total thermal resistance will be the sum of a convective resistance and two conductive resistances.

Thermodynamic modeling of this system can be written based on the following assumptions.

$>$ The thermal properties of the soil are isotropic.

The modeling is done based on steady-state conditions.

$>$ A perfect contact exists between the pipe and bounded soil.

$>$ The depth of the buried pipe is constant throughout the whole Length.

D The physical properties of the fluid are constant.

Therefore, the convective resistance due to the transfer of heat from flowing air to the inner surface of the pipe may be formulated as:

$$
R_{c}=\frac{1}{2 \pi r_{i} l_{p} h}
$$

The conductive thermal resistance due to pipe thickness and heat transfer has taken place from the inner surface of the pipe to the outer surface of the pipe may be formulated as,

$$
R_{\text {pipe }}=\frac{\ln \left(\frac{r_{o}}{r_{i}}\right)}{2 \pi K_{p} l_{p}}
$$

The conductive thermal resistance due to transfer of heat from the outer surface of the pipe to bounded soil has been calculated using relation from Holman [17].

$$
R_{\text {soil }}=\frac{\operatorname{Cos}^{-1} h\left(\frac{d}{r_{o}}\right)}{2 \pi l_{p} K_{s}}
$$

Thus total thermal resistance would be:

$$
\begin{gathered}
R_{\text {total }}=R_{c}+R_{p}+R_{s} \\
R_{\text {total }}=\frac{1}{2 \pi r_{i} l_{p} h}+\frac{\ln \left(\frac{r_{o}}{r_{i}}\right)}{2 \pi K_{p} l_{p}}+\frac{\operatorname{Cos}^{-1} h\left(\frac{d}{r_{o}}\right)}{2 \pi l_{p} K_{s}} \\
R_{\text {total }}=\frac{1}{l_{p}}\left(\frac{1}{2 \pi r_{i} h}+\frac{\ln \left(\frac{r_{o}}{r_{i}}\right)}{2 \pi K_{p}}+\frac{\operatorname{Cos}^{-1} h\left(\frac{d}{r_{o}}\right)}{2 \pi K_{s}}\right)
\end{gathered}
$$

Let us consider,

$$
X=\left(\frac{1}{2 \pi r_{i} h}+\frac{\ln \left(\frac{r_{o}}{r_{i}}\right)}{2 \pi K_{p}}+\frac{\cos ^{-1} h\left(\frac{d}{r_{o}}\right)}{2 \pi K_{s}}\right)
$$

Since X has been introduced for simplicity of calculation, which results from different dimensions and properties of parameters.

Therefore,

$$
R_{\text {total }}=\frac{X}{l_{p}}
$$

In the formula of convective resistance, the term convective heat transfer coefficient (h) may be found using the Nusselt number.

Nusselt number is given as:

$$
N u=\frac{h \times D_{i}}{K_{a}}
$$

Since, Nusselt number is the function of Reynolds number and Prandtl number. i.e

$$
N u=f(\operatorname{Re}, \operatorname{Pr})
$$

We have available empirical relation for the calculation of Nusselt number.

For Laminar flow, that is where the Reynolds number is less than $2300(\operatorname{Re}<2300)$.

$$
N u=4.36
$$

For fully developed turbulent flow in the buried pipe where Prandtl number lies between 0.5 to 2000 , and Reynolds number lies between 2300 to $5 \times 10^{6}$.

The given empirical relation for Nusselt number is:

$$
N u=\frac{\left(\frac{f}{8}\right) \times(\operatorname{Re}-1000) \times \operatorname{Pr}}{1+12.7\left(\frac{f}{8}\right)^{\frac{1}{2}}\left(\operatorname{Pr}^{\frac{2}{3}}-1\right)}
$$

Here $\mathrm{f}$ is the friction factor and may be calculated as,

$$
f=[0.79 \times \ln (\operatorname{Re})-1.64]^{-2}
$$

And Re is the Reynolds number and may be calculated as:

$$
\operatorname{Re}=\frac{\rho \times v \times D_{i}}{\mu}
$$

And Pr is the Prandlt number and may be calculated as:

$$
\operatorname{Pr}=\frac{\mu \times C_{a}}{K_{a}}
$$

The effectiveness of the system in the form of temperature may be calculated as: 


$$
\varepsilon=\frac{T_{i}-T_{o}}{T_{i}-T_{s}}
$$

However, the effectiveness of the system may also be computed by Zukowski and Topolanska [18].

$$
\begin{aligned}
\varepsilon & =1-e^{-N T U} \\
& =1-e^{\frac{-U A}{m_{a} C_{a}}}
\end{aligned}
$$

Since

$$
U A=\frac{1}{R_{\text {total }}}
$$

Now, Putting the value of total thermal resistance in Eq. (18), we get

$$
U A=\frac{l_{p}}{X}
$$

Hence in this way, by putting the respective values in the above equations, we easily calculated both the key parameters of the Earth air tube heat exchanger.

\section{OPTIMIZATION METHODOLOGY}

\subsection{Taguchi technique}

Taguchi technique is a powerful tool that is often used in robust design to search the least sensitive to noise processes and conditions to get high-quality products with minimum manufacturing cost. Taguchi methods require fewer data and give better graphical visualization to determine optimum condition by calculating signal to noise ratio than response surface methodology. So, if the experimental run is more timeconsuming and costly, it is more convenient to use Taguchi over RSM. Taguchi design is an efficient optimization tool in preliminary studies to screen parameters that significantly affect the result.

It recommends a matrix of experiments using specially designed tables called an orthogonal array. By planning, conducting, and evaluating this experiment matrix's results, we may collect the maximum information from entire parameters with a minimum number of trails and obtain the optimum levels of each and every control parameter in our objective key function. The various steps involved in the implementation of the technique have been given in Figure 2.

\subsection{Taguchi design of experiment}

In order to perform this statistical optimization technique in our research, we have taken six factors each at three levels. All these factors, with their respective levels that are to be studied, are compiled in Table 1. Now minimum numbers of experimental trials have been fixed using a relation given in Eq. (20). After this, we select orthogonal array (OA) upon which this technique has been applied for getting signal to noise ratio, which in turn gave the optimal combination of

\begin{tabular}{|c|c|c|c|c|c|c|}
\hline $\begin{array}{l}\text { Experiment } \\
\text { No. }\end{array}$ & $\begin{array}{l}\text { Factor } \\
\text { (A) }\end{array}$ & $\begin{array}{c}\text { Factor } \\
\text { (B) }\end{array}$ & $\begin{array}{c}\text { Factor } \\
\text { (C) }\end{array}$ & $\begin{array}{l}\text { Factor } \\
\text { (D) }\end{array}$ & $\begin{array}{c}\text { Factor } \\
\text { (E) }\end{array}$ & $\begin{array}{l}\text { Factor } \\
\text { (F) }\end{array}$ \\
\hline 1 & 1 & 1 & 1 & 1 & 1 & 1 \\
\hline 2 & 1 & 1 & 1 & 1 & 2 & 2 \\
\hline 3 & 1 & 1 & 1 & 1 & 3 & 3 \\
\hline 4 & 1 & 2 & 2 & 2 & 1 & 1 \\
\hline 5 & 1 & 2 & 2 & 2 & 2 & 2 \\
\hline 6 & 1 & 2 & 2 & 2 & 3 & 3 \\
\hline 7 & 1 & 3 & 3 & 3 & 1 & 1 \\
\hline 8 & 1 & 3 & 3 & 3 & 2 & 2 \\
\hline 9 & 1 & 3 & 3 & 3 & 3 & 3 \\
\hline 10 & 2 & 1 & 2 & 3 & 1 & 2 \\
\hline 11 & 2 & 1 & 2 & 3 & 2 & 3 \\
\hline 12 & 2 & 1 & 2 & 3 & 3 & 1 \\
\hline 13 & 2 & 2 & 3 & 1 & 1 & 2 \\
\hline 14 & 2 & 2 & 3 & 1 & 2 & 3 \\
\hline 15 & 2 & 2 & 3 & 1 & 3 & 1 \\
\hline 16 & 2 & 3 & 1 & 2 & 1 & 2 \\
\hline 17 & 2 & 3 & 1 & 2 & 2 & 3 \\
\hline 18 & 2 & 3 & 1 & 2 & 3 & 1 \\
\hline 19 & 3 & 1 & 3 & 2 & 1 & 3 \\
\hline 20 & 3 & 1 & 3 & 2 & 2 & 1 \\
\hline 21 & 3 & 1 & 3 & 2 & 3 & 2 \\
\hline 22 & 3 & 2 & 1 & 3 & 1 & 3 \\
\hline 23 & 3 & 2 & 1 & 3 & 2 & 1 \\
\hline 24 & 3 & 2 & 1 & 3 & 3 & 2 \\
\hline 25 & 3 & 3 & 2 & 1 & 1 & 3 \\
\hline 26 & 3 & 3 & 2 & 1 & 2 & 1 \\
\hline 27 & 3 & 3 & 2 & 1 & 3 & 2 \\
\hline
\end{tabular}
levels of these factors for objective functions.
Table 1. Different factor and their levels

\begin{tabular}{ccccc}
\hline Factor & Parameters & $\begin{array}{c}\text { Level } \\
\mathbf{1}\end{array}$ & $\begin{array}{c}\text { Level } \\
\mathbf{2}\end{array}$ & $\begin{array}{c}\text { Level } \\
\mathbf{3}\end{array}$ \\
\hline $\mathrm{A}$ & $\begin{array}{c}\text { Installation depth of } \\
\text { ground heat exchanger } \\
\text { pipe }(\mathrm{m})\end{array}$ & 1 & 1.5 & 2 \\
\hline $\mathrm{B}$ & $\begin{array}{c}\text { Inner diameter of the pipe } \\
(\mathrm{m})\end{array}$ & 0.05 & 0.1 & 0.15 \\
\hline $\mathrm{C}$ & $\begin{array}{c}\text { Thermal conductivity of } \\
\text { pipe material (W/mK) }\end{array}$ & 0.15 & 0.2 & 0.25 \\
\hline $\mathrm{D}$ & Inlet air temperature $(\mathrm{K})$ & 305 & 309 & 313 \\
\hline $\mathrm{E}$ & Outlet air temperature $(\mathrm{K})$ & 298 & 299.5 & 301 \\
\hline $\mathrm{F}$ & Inlet air velocity (m/s) & 1 & 1.5 & 2 \\
\hline & & & &
\end{tabular}

Table 2. The general layout of $L_{27}$ orthogonal array

where, $\mathrm{N}_{\text {Taguchi }}$ shows the least possible number of experimental trails recommended for performing the optimization, NV shows the number of control parameters or variables are chosen, and L shows the number of levels selected for variables. In our present optimization study, $\mathrm{NV}=6$ and $\mathrm{L}=3$. So here, a minimum number of experimental trials have to be performed thirteen, and the nearest orthogonal array is $\mathrm{L}_{18}$ for a given mixed level of experimental runs. However, in the present research, we considered only a single level trail, so we select here $\mathrm{L}_{27}$ experimental trails. Hence all the computational work is carried out in this research is according to $\mathrm{L}_{27}$ combinations of an orthogonal array. So the standard layout of $\mathrm{L}_{27}$ orthogonal array with three levels is compiled in Table 2. As per our present research, the main objective is to calculate the optimum ground heat exchanger length and overall heat transfer coefficient for EATHE. The lower is better criterion has opted for calculation of $\mathrm{SN}$ ratio 
in case of ground heat exchanger length because our objective is to lessen the ground heat exchanger length, while higher is better characteristics is applied for calculation of $\mathrm{SN}$ ratio in case of overall heat transfer coefficient. Hence the formulae for both the characteristics are as given below.

The lower is better characteristics are expressed as,

$$
S / N_{L B}=-10 \log \left(\frac{1}{r} \sum_{i=1}^{r} y_{i}^{2}\right)
$$

The higher is better characteristics are expressed as,

$$
S / N_{H B}=-10 \log _{10}\left(\frac{1}{r} \sum_{i=1}^{r} \frac{1}{y_{i}^{2}}\right)
$$

where, in both above equations, $y_{i}$ is the performance value at the given observation, and $i$ is the number of repetitions in an experimental trial.

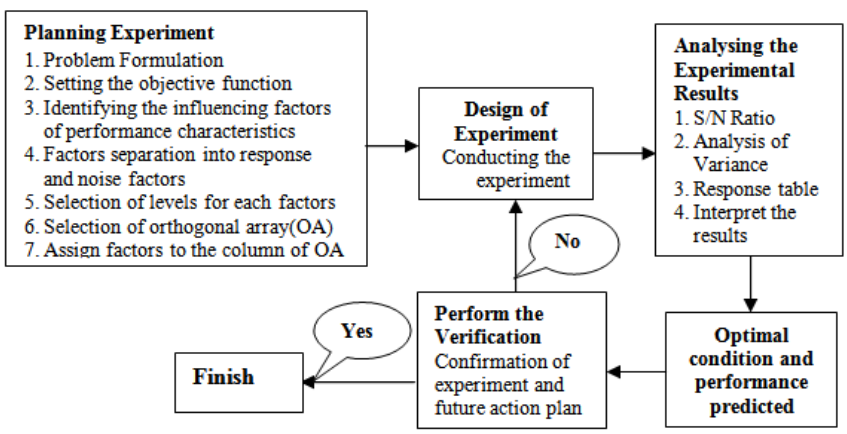

Figure 2. Various steps in Taguchi optimization

\section{RESULTS AND DISCUSSION}

Our prime aim of the research is to get the minimum length of the ground heat exchanger and maximum value of the overall heat transfer coefficient for the cooling application of the EATHE system. Since these objective parameters are greatly affected by various parameters such as depth of the buried pipe, the inner and outer diameter of the pipe, the material of the pipe, the thermal conductivity of pipe material, the thermal conductivity of soil, the specific heat of air, inlet velocity of air, viscosity of air, the mass flow rate of air, inlet and outlet temperature of the air, among all these parameters some are fixed while other parameters are controllable in the process of optimization. Hence in this paper, initially six parameters have been considered as control factors: depth of pipe (A), Diameter of pipe (B), Thermal conductivity of Pipe material (C), the inlet temperature of air (D), outlet air temperature $(\mathrm{E})$, Inlet air velocity $(\mathrm{F})$. All these factors are selected with three levels for analysis to optimize the system by using the Taguchi technique for the cooling mode of applications. Hence Table 3 indicates the actual values of levels of all six selected factors for all 27 experimental trails.

The data provided in every experimental trail shown in Table 3 is sufficient for computational purposes, such as calculating ground heat exchanger length and overall heat transfer coefficient using the respective equations as given in section 3 of this paper. Hence the calculated results of ground heat exchanger length and overall heat transfer coefficient using all the required parameters and fixed values for each experimental trail have been compiled in Table 4.

The following sub-section of this chapter indicates the results that have been computed to optimize this system.

\begin{tabular}{|c|c|c|c|c|c|c|}
\hline $\begin{array}{c}\text { Experiment } \\
\text { No. } \\
\end{array}$ & $\begin{array}{l}\text { Factor } \\
\text { (A) }\end{array}$ & $\begin{array}{l}\text { Factor } \\
\text { (B) }\end{array}$ & $\begin{array}{l}\text { Factor } \\
\text { (C) }\end{array}$ & $\begin{array}{l}\text { Factor } \\
\text { (D) }\end{array}$ & $\begin{array}{l}\text { Factor } \\
\text { (E) }\end{array}$ & $\begin{array}{c}\text { Factor } \\
(\mathbf{F})\end{array}$ \\
\hline 1 & 1 & 0.05 & 0.15 & 305 & 298 & 1 \\
\hline 2 & 1 & 0.05 & 0.15 & 305 & 299.5 & 1.5 \\
\hline 3 & 1 & 0.05 & 0.15 & 305 & 301 & 2 \\
\hline 4 & 1 & 0.1 & 0.2 & 309 & 298 & 1 \\
\hline 5 & 1 & 0.1 & 0.2 & 309 & 299.5 & 1.5 \\
\hline 6 & 1 & 0.1 & 0.2 & 309 & 301 & 2 \\
\hline 7 & 1 & 0.15 & 0.25 & 313 & 298 & 1 \\
\hline 8 & 1 & 0.15 & 0.25 & 313 & 299.5 & 1.5 \\
\hline 9 & 1 & 0.15 & 0.25 & 313 & 301 & 2 \\
\hline 10 & 1.5 & 0.05 & 0.2 & 313 & 298 & 1.5 \\
\hline 11 & 1.5 & 0.05 & 0.2 & 313 & 299.5 & 2 \\
\hline 12 & 1.5 & 0.05 & 0.2 & 313 & 301 & 1 \\
\hline 13 & 1.5 & 0.1 & 0.25 & 305 & 298 & 1.5 \\
\hline 14 & 1.5 & 0.1 & 0.25 & 305 & 299.5 & 2 \\
\hline 15 & 1.5 & 0.1 & 0.25 & 305 & 301 & 1 \\
\hline 16 & 1.5 & 0.15 & 0.15 & 309 & 298 & 1.5 \\
\hline 17 & 1.5 & 0.15 & 0.15 & 309 & 299.5 & 2 \\
\hline 18 & 1.5 & 0.15 & 0.15 & 309 & 301 & 1 \\
\hline 19 & 2 & 0.05 & 0.25 & 309 & 298 & 2 \\
\hline 20 & 2 & 0.05 & 0.25 & 309 & 299.5 & 1 \\
\hline 21 & 2 & 0.05 & 0.25 & 309 & 301 & 1.5 \\
\hline 22 & 2 & 0.1 & 0.15 & 313 & 298 & 2 \\
\hline 23 & 2 & 0.1 & 0.15 & 313 & 299.5 & 1 \\
\hline 24 & 2 & 0.1 & 0.15 & 313 & 301 & 1.5 \\
\hline 25 & 2 & 0.15 & 0.2 & 305 & 298 & 2 \\
\hline 26 & 2 & 0.15 & 0.2 & 305 & 299.5 & 1 \\
\hline 27 & 2 & 0.15 & 0.2 & 305 & 301 & 1.5 \\
\hline
\end{tabular}

Table 3. $\mathrm{L}_{27}$ experimental plan

Table 4. Results and $\mathrm{S} / \mathrm{N}$ ratios of $\mathrm{GXH}$ and $\mathrm{U}$

\begin{tabular}{ccccc}
\hline $\begin{array}{c}\text { Experiment } \\
\text { No. }\end{array}$ & $\begin{array}{c}\text { GXH } \\
\text { Length } \\
(\mathbf{m})\end{array}$ & $\begin{array}{c}\mathbf{U} \\
\left(\mathbf{W} / \mathbf{m}^{2}\right. \\
\mathbf{K})\end{array}$ & $\begin{array}{c}\text { S/N ratio of } \\
\text { GXH Length }\end{array}$ & $\begin{array}{c}\text { S/N ratio of } \\
\mathbf{U}\end{array}$ \\
\hline 1 & 10.09 & 5.2 & -20.0778 & 14.32007 \\
2 & 8.3 & 4.3 & -18.3816 & 12.66937 \\
3 & 6.52 & 3.38 & -16.285 & 10.57833 \\
4 & 34.31 & 24.51 & -30.7084 & 27.78687 \\
5 & 31.51 & 22.67 & -29.969 & 27.10903 \\
6 & 29.89 & 21.5 & -29.5105 & 26.64877 \\
7 & 71.96 & 60.98 & -37.1418 & 35.70375 \\
8 & 69.1 & 59.57 & -36.7896 & 35.50055 \\
9 & 69.98 & 60.33 & -36.8995 & 35.61067 \\
10 & 19.44 & 10.34 & -25.7739 & 20.29041 \\
11 & 16.79 & 8.98 & -24.501 & 19.06553 \\
12 & 6.44 & 3.41 & -16.1777 & 10.65509 \\
13 & 44.97 & 30.8 & -33.0585 & 29.77101 \\
14 & 32.87 & 22.67 & -30.336 & 27.10903 \\
15 & 9.75 & 6.68 & -19.7801 & 16.49553 \\
16 & 116.13 & 82.36 & -41.2989 & 38.31433 \\
17 & 95.47 & 67.71 & -39.5973 & 36.61306 \\
18 & 34.45 & 24.09 & -30.7438 & 27.63674 \\
19 & 22.96 & 12.41 & -27.2194 & 21.87544 \\
20 & 7.16 & 3.83 & -17.0983 & 11.66398 \\
21 & 7.59 & 4.08 & -17.6048 & 12.2132 \\
22 & 93.09 & 54.44 & -39.3781 & 34.71836 \\
23 & 30.67 & 17.73 & -29.7343 & 24.97417 \\
24 & 34.74 & 20.2 & -30.8166 & 26.10703 \\
25 & 130.67 & 92.02 & -42.3235 & 39.27764 \\
26 & 36.56 & 25.39 & -31.2601 & 28.09325 \\
27 & 32.12 & 22.46 & -30.1355 & 27.0282 \\
\hline & & & &
\end{tabular}


In the Taguchi technique, after carrying out the required experimental trails, we convert the trails' results in to signal to noise ratio ( $\mathrm{S} / \mathrm{N}$ ratio). In signal to noise ratio, the term signal indicates the desirable effect of trails' output results while noise indicates the undesirable effects of each trail's output results. In this research, we have calculated the $\mathrm{S} / \mathrm{N}$ ratio using the lower is better characteristics concept for ground heat exchanger length while the higher is better characteristics concept was applied for calculation of signal to noise ratio for overall heat transfer coefficient. Therefore, the calculated values of signal to noise ratios for both the parameters of each trail are compiled in Table 4.

For all these six factors, the mean response of $\mathrm{S} / \mathrm{N}$ ratios for output results at each level has been computed using the software named MiniTab. The calculated mean responses for ground heat exchanger length and overall heat transfer coefficient have been compiled in Table 5 and Table 6, respectively. Also, each factor's delta values and rank for both the results have been computed and inserted in their respective tables. The order of influence of the parameters for ground heat exchanger length and overall heat transfer coefficient indicates by giving rank in their respective tables. Therefore, we may easily be recognized by each factor's rank, which are most influencing and least influencing factors among all the six factors; that is, rank 1 indicates the most influencing factor, and rank 6 indicates the least influencing factors.

Now according to the results of the response of $\mathrm{S} / \mathrm{N}$ ratios, as shown in Table 5 and 6 , we may get the best combination set of parameters by identifying the level with the least value of each factor in case of ground heat exchanger length while maximum values in case of overall heat transfer coefficient. Thus from Table 5 for ground heat exchanger length, we easily select the optimum levels of all six control parameters and are given as A1B1C3D1E3F1. Similarly, for the overall heat transfer coefficient using Table 6, we have been selected optimum levels of all six parameters as A2B3C2D3E1F3.

The calculated values of responses of the $\mathrm{S} / \mathrm{N}$ ratio for ground heat exchanger length and overall heat transfer coefficient as tabulated in Tables 5 and 6 are depicted in Figures 3 and 4 respectively by making graphs for better understanding. Figure 3 indicates the fluctuation of the $\mathrm{S} / \mathrm{N}$ ratio against given levels of all the six factors for ground heat exchanger length. Same as Figure 4 indicates the fluctuation of the $\mathrm{S} / \mathrm{N}$ ratio against various levels of all the six factors for the overall heat transfer coefficient.

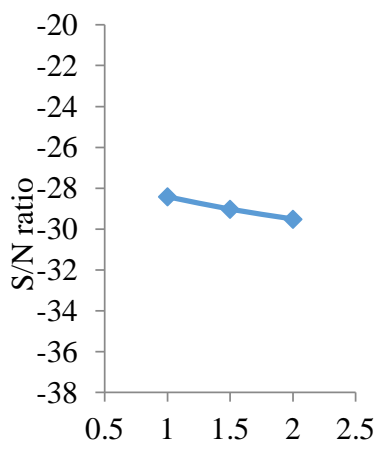

Installation depth of Pipe (m)

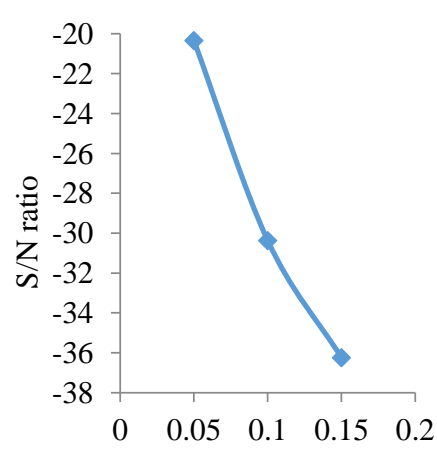

Inner diameter of Pipe (m)
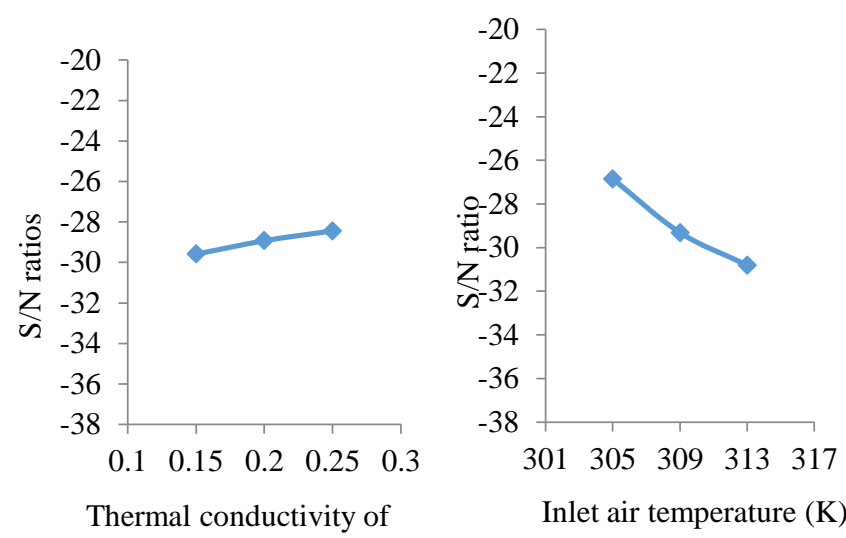

Thermal conductivity of Pipe $(\mathrm{W} / \mathrm{mK})$

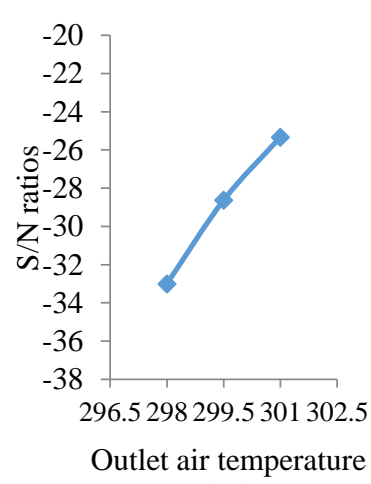

$(\mathrm{K})$

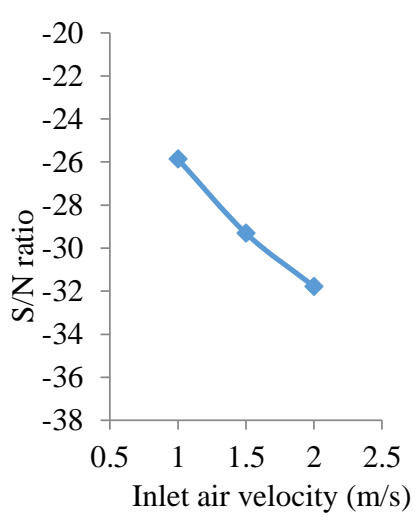

Figure 3. Mean of $\mathrm{S} / \mathrm{N}$ ratios of all six factors for GXH length

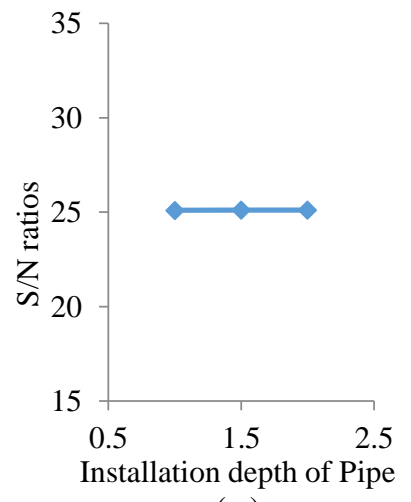

(m)

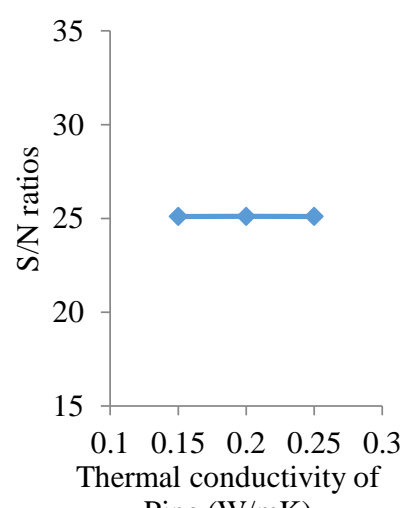

Pipe (W/mK)

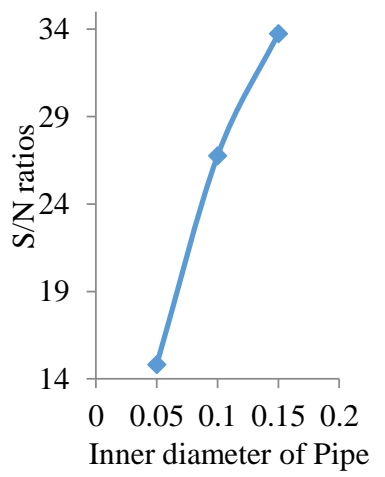

(m)

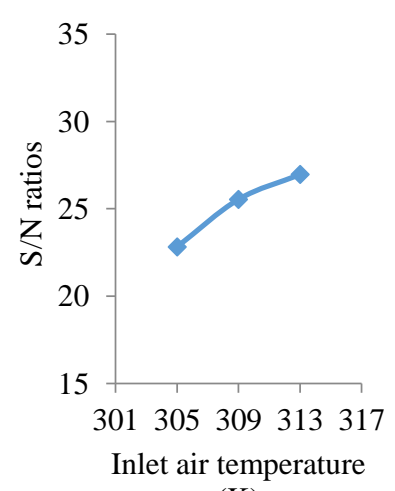

(K) 


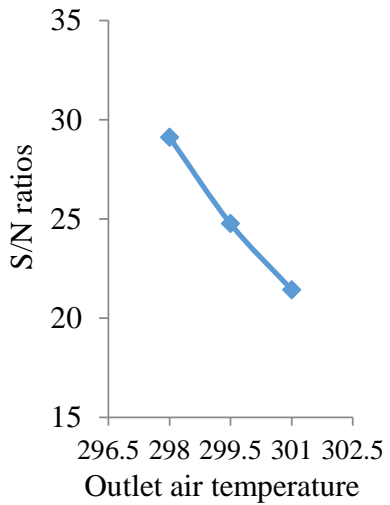

$(\mathrm{K})$

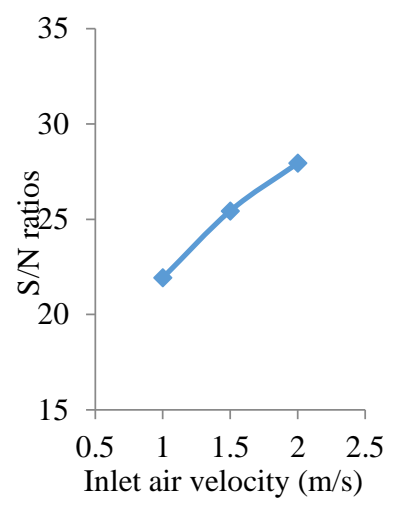

Figure 4. Mean of $\mathrm{S} / \mathrm{N}$ ratios of all six factors for $\mathrm{U}$

Table 5. Response table for GXH

\begin{tabular}{ccccccc}
\hline Level & A & B & C & D & E & F \\
\hline 1 & -28.42 & -20.35 & -29.59 & -26.85 & -33.00 & -25.86 \\
\hline 2 & -29.03 & -30.37 & -28.93 & -29.31 & -28.63 & -29.31 \\
\hline 3 & -29.51 & -36.24 & -28.44 & -30.80 & -25.33 & -31.78 \\
\hline Delta & 1.09 & 15.90 & 1.15 & 3.95 & 7.67 & 5.93 \\
\hline Rank & 6 & 1 & 5 & 4 & 2 & 3 \\
\hline
\end{tabular}

Table 6. Response Table for U

\begin{tabular}{ccccccc}
\hline Level & A & B & C & D & E & F \\
\hline 1 & 25.10 & 14.81 & 25.10 & 22.82 & 29.12 & 21.93 \\
\hline 2 & 25.11 & 26.75 & 25.11 & 25.54 & 24.76 & 25.44 \\
\hline 3 & 25.11 & 33.75 & 25.10 & 26.96 & 21.44 & 27.94 \\
\hline Delta & 0.00 & 18.94 & 0.00 & 4.14 & 7.68 & 6.02 \\
\hline Rank & 5 & 1 & 6 & 4 & 2 & 3
\end{tabular}

\subsection{Taguchi Technique-Analysis of Variance (ANOVA)}

Analysis of variance (ANOVA) is adopted to evaluate which factors are statistically significant among all available control factors by determining the percentage contribution of each factor. In ANOVA analysis, we make a table called ANOVA table that contains the degree of freedom (DF), Sum of squares (SS), Mean of squares (MS), F ratio, and percentage contribution. The ranking of relative significance for each factor is done according to their percentage contribution. The highest percentage contribution containing factor is ranked highest and has a prime contribution to the overall response. Hence DOF, SS, MS, F-ratio, and percentage contribution of all the factors were calculated using Eq. (23-30) for space cooling purposes.

Table 7 and Table 8 represents ANOVA values for ground heat exchanger and overall heat transfer coefficient, respectively. The value of f-ratio helps us recognize the factor that has a significant effect on ground heat exchanger length and overall heat transfer coefficient. The various governing equations used in ANOVA are given as follows [19].

$$
\begin{aligned}
& \text { DOF }=\text { Level }-1 \\
& \mathrm{SS}_{\mathrm{m}}=\frac{\left(\sum \eta_{\mathrm{i}}\right)^{2}}{\mathrm{n}}
\end{aligned}
$$

$$
\begin{gathered}
\mathrm{ss}_{\text {factor }}=\frac{\sum \eta_{\text {factor }-\mathrm{i}}^{2}-\mathrm{SS}_{\mathrm{m}}}{\mathrm{N}} \\
\mathrm{SS}_{\mathrm{T}}=\sum \eta_{\mathrm{i}}^{2}-\mathrm{SS}_{\mathrm{m}} \\
\mathrm{SS}_{\mathrm{e}}=\mathrm{SS}_{\mathrm{T}}-\sum \mathrm{SS}_{\text {factor }} \\
\mathrm{MS}_{\text {factor }}-\frac{\mathrm{SS}_{\text {factor }}}{\mathrm{DOF}_{\text {factor }}} \\
\mathrm{F}_{\text {factor }}=\frac{\mathrm{MS}_{\text {factor }}}{\mathrm{MS}_{\mathrm{e}}} \\
\% \text { Contribution }=\frac{\mathrm{SS}_{\text {factor }}}{\sum \mathrm{SS}_{\text {factor }}} \mathrm{X} 100
\end{gathered}
$$

Table 7. ANOVA: Ground heat exchanger length

\begin{tabular}{cccccc}
\hline Factors & DOF & SS & MS & F-ratio & $\begin{array}{c}\text { Percentage } \\
\text { Contribution }\end{array}$ \\
\hline A & 2 & 5.37 & 2.69 & 3.54 & 0.32 \\
\hline B & 2 & 1163.09 & 581.55 & 765.2 & 69.12 \\
\hline C & 2 & 6.03 & 3.02 & 3.97 & 0.36 \\
\hline D & 2 & 71.68 & 35.84 & 47.16 & 4.26 \\
\hline E & 2 & 266.43 & 133.22 & 175.29 & 15.83 \\
\hline F & 2 & 159.47 & 79.74 & 104.92 & 9.48 \\
\hline Error & 14 & 10.69 & 0.76 & & 0.64 \\
\hline
\end{tabular}

Table 8. ANOVA: Overall heat transfer coefficient

\begin{tabular}{cccccc}
\hline Factors & DOF & SS & MS & F-ratio & $\begin{array}{c}\text { Percentage } \\
\text { Contribution }\end{array}$ \\
\hline A & 2 & 0 & 0 & 0 & 0 \\
\hline B & 2 & 1650.17 & 825.09 & 1057.81 & 75.97 \\
\hline C & 2 & 0 & 0 & 0 & 0 \\
\hline D & 2 & 79.75 & 39.88 & 51.13 & 3.67 \\
\hline E & 2 & 266.7 & 133.35 & 170.96 & 12.28 \\
\hline F & 2 & 164.61 & 82.31 & 105.53 & 7.58 \\
\hline Error & 14 & 10.86 & 0.78 & & 0.5 \\
\hline
\end{tabular}

\subsubsection{Ground heat exchanger length}

As per the calculated values of ANOVA for ground heat exchanger length that has been compiled in Table 7, we found that the inner diameter of the pipe (B) and Outlet air temperature (E) with contribution percentage of $69.12 \%$ and $15.83 \%$ respectively, are substantial contributing factors. The percentage contributions of remaining parameters such as inlet air velocity (F), Inlet air temperature (D), Thermal conductivity of pipe material (C), and the Installation depth of ground heat exchanger pipe (A) are found to be $9.48 \%, 4.26 \%$, $0.36 \%$, and $0.32 \%$ respectively. Therefore, from this table, the contributing factors ranked as BEFDCA.

\subsubsection{Overall heat transfer coefficient}

As per the calculated values of ANOVA for the overall heat transfer coefficient that has been compiled in Table 8 , we found that the inner diameter of the pipe (B) and Outlet air temperature (E) with contribution percentage of $75.97 \%$ and $12.28 \%$ respectively, are substantial contributing factors. The percentage contributions of remaining factors such as inlet air 
velocity (F), Inlet air temperature (D), Thermal conductivity of pipe material (C), and the Installation depth of ground heat exchanger pipe (A) are found to be $7.58 \%, 3.67 \%, 0 \%$, and $0 \%$ respectively. Therefore, from this table, the contributing factors ranked as BEFDCA.

\subsection{Confirmations test}

The Length of the ground heat exchanger, and the overall heat transfer coefficient were analyzed. We have made all the required calculations for all experimental trials using the data given in Table 3. The ground heat exchanger length and overall heat transfer coefficient were determined and compiled in table 4. From these results, we may observe that the range of ground heat exchanger length and overall heat transfer coefficient varies from $6.44 \mathrm{~m}$ to $130.67 \mathrm{~m}$, and 3.38 to $3.77 \mathrm{~W} / \mathrm{m}^{2} \mathrm{~K}$, respectively. According to the leading set of operating parameters in the orthogonal array, the optimum value of ground heat exchanger length and overall heat transfer coefficient is evaluated as $2.79 \mathrm{~m}$ and $121.97 \mathrm{~W} / \mathrm{m}^{2} \mathrm{~K}$. Among all the 27 experimental runs, the optimum value of ground heat exchanger length and overall heat transfer coefficient is minimum and maximum, respectively.

\section{CONCLUSIONS}

This research work optimized ground heat exchanger length and overall heat transfer coefficient of earth air tube heat exchanger using the Taguchi technique for space cooling application. Hence, L27 orthogonal array with six factors, and each factor was assigned at three levels, and computations for all these experimental trials have been performed. For optimizing these factors, we applied the $\mathrm{S} / \mathrm{N}$ ratio and ANOVA technique. Based on Taguchi's results, we conclude the following outcomes.

- The most influencing parameter for ground heat exchanger length, as well as the overall heat transfer coefficient, is the inner diameter of the pipe with a contribution factor of $69.12 \%$ and $75.97 \%$, respectively.

- The ranges of maximum influencing and minimum influencing factor for the ground heat exchanger are $69.12 \%$ to 0.32 , while that for the heat transfer coefficient was $75.97 \%$ to $0 \%$, respectively.

- The least influencing parameter for ground heat exchanger length is burial depth, while for overall heat transfer coefficient is the least influencing parameters in the burial depth and thermal conductivity of pipe.

- The optimal condition of all the six parameters for the lowest required Length of ground heat exchanger isA1B1C3D1E3F1, while for getting maximum overall heat transfer coefficient, the optimal condition is A2B3C2D3E1F3.

\section{REFERENCES}

[1] Popiel, C.O., Wojtkowaik, J. (2013). Temperature distributions of ground in the urban region of Poznan City. Experimental Thermal and Fluid Science, 51: 135148. https://doi.org/10.1016/j.expthermflusci.2013.07.009

[2] Al-Hinti, I., Al-Muhtady, A., Al-Kouz, W. (2017). Measurement and modeling of the ground temperature profile in Zarqa, Jordan, for geothermal heat pump applications. Applied Thermal Engineering, 123: 131137.

http://dx.doi.org/10.1016/j.applthermaleng.2017.05.107

[3] Abbaspour-Fard, M.H., Gholami, A., Khojastehpour, M. (2011). Evaluation of an earth-to-air heat exchanger for the north-east of Iran with semi-arid climate. International Journal of Green Energy, 8(4): 499-510. http://dx.doi.org/10.1080/15435075.2011.576289

[4] Sehli, A., Hasni, A., Tamali, M. (2012). The potential of earth-air heat exchangers for low energy cooling of buildings in South Algeria. Energy Procedia, 18: 496506. https://doi.org/10.1016/j.egypro.2012.05.061

[5] Singh, S.P. (1994). Optimization of earth air tunnel system for space cooling. Energy Conversion and Management, 33(8): 721-725. https://doi.org/10.1016/0196-8904(94)90057-4

[6] Spengler, R.W., Stombaugh, D.P. (1983). Optimization of earth-tube heat exchangers for winter ventilation of swine housing. Transactions of the ASAE, 26(4): 11861193. http://dx.doi.org/10.13031/2013.34102

[7] Agrawal, K.K., Bhardwaj, M., Misra, R., Agrawal, G.D., Bansal, V. (2018). Optimization of operating parameters of earth air tunnel heat exchanger for space cooling: Taguchi method approach. Geotherm Energy, 6(10): 117. https://doi.org/10.1186/s40517-018-0097-0

[8] Sivasakthivel, T., Murugesan, K., Thomas, H.R. (2014). Optimization of operating parameters of ground source heat pump system for space heating and cooling by Taguchi method and utility concept. Applied Energy, 116: http://dx.doi.org/10.1016/j.apenergy.2013.10.065

[9] Pandey, N., Murugesan, K., Thomas, H.R. (2017). Optimization of ground heat exchangers for space heating and cooling applications using the Taguchi method and utility concept. Applied Energy, 190: 421438. http://dx.doi.org/10.1016/j.apenergy.2016.12.154

[10] Verma, V., Murugesan, K. (2014). Optimization of solar assisted ground source heat pump system for space heating application by Taguchi method and utility concept. Energy and Buildings, 82: 296-309. http://dx.doi.org/10.1016/j.enbuild.2014.07.029

[11] Baglivo, C., D’Agostino, D., Congedo, P.M. (2018). Design of a ventilation system coupled with a Horizontal Air-Ground Heat Exchanger (HAGHE) for a residential building in a warm climate. Energies, 11(8): 2122. https://doi.org/10.3390/en11082122

[12] Kumar, R., Sinha, A.R., Singh, B.K., Modhukalya, U. (2008). A design optimization tool of earth-to-air heat exchanger using a genetic algorithm. Renewable Energy, 33: 2282-2288 https://doi.org/10.1016/j.renene.2008.01.006

[13] Carlucci, S., Cattarin, G., Pagliano, L., Pietrobon, M. (2014). Optimization of the installation of an Earth-toAir Heat Exchanger and detailed design of a dedicated experimental set-up. Applied Mechanics and Materials, 501: 2158-2161. https://doi.org/10.4028/www.scientific.net/AMM.501504.2158

[14] Kaushal, M., Dhiman, P., Singh, S., Patel, H. (2015). Finite volume and response surface methodology based performance prediction and optimization of a hybrid earth to air tunnel heat exchanger. Energy and Buildings, 104:

25-35. 
https://doi.org/10.1016/j.enbuild.2015.07.014

[15] Tiwari, G.N., Singh, V., Joshi, P., Shyam, V., Deo, A., Prabhakant, D., Gupta, A. (2014). Design of an Earth Air Heat Exchanger (EATHE) for climatic condition of chennai, India. Open Environmental Sciences, 8: 24-34. https://doi.org/10.2174/1876325101408010024

[16] Diaz, S.E, Sierra, J.M.T., Herrera, J.A. (2014). The use of earth-air heat exchanger and fuzzy logic control can reduce energy consumption and environmental concerns even more. Energy and Buildings, 65: 458-463. https://doi.org/10.1016/j.enbuild.2013.06.028

[17] Holman, J.P. (2010). Heat Transfer. The McGraw-Hill Companies, New York, 84.

[18] Zukowski, M., Topolanska, J. (2018). Comparison of thermal performance between tube and plate ground air heat exchangers. Renewable Energy, 115: 697-710. https://doi.org/10.1016/j.renene.2017.09.001

[19] Esen, H., Turgut, E. (2015). Optimization of operating parameters of a ground coupled heat pump system by Taguchi method. Energy and Buildings, 107: 329-334. http://dx.doi.org/10.1016/j.enbuild.2015.08.042

\section{NOMENCLATURE}

EATHE
GXH
ANOVA
DOF
SS
MS
T
U
h
k
$\mathrm{m}$

earth air tube heat exchanger

ground heat exchanger

analysis of variance

degree of freedom

sum of squares

mean of squares

temperature

over all heat transfer coefficient, $w / \mathrm{m}^{2} \mathrm{k}$

convective heat transfer coefficient

thermal conductivity, w. $\mathrm{m}^{-1}$. $\mathrm{K}^{-1}$

mass flow rate, kg.s ${ }^{-1}$
C

$\mathrm{D}$

r

d

1

$\mathrm{f}$

$\mathrm{Nu}$

$\mathrm{Re}$

$\operatorname{Pr}$

NV

$\mathrm{L}$

\section{Greek symbols}

\section{Subscripts}

$\mathrm{S} / \mathrm{N}$ ratio

$\mathrm{R}$

specific heat, j. $\mathrm{Kg}^{-1} \cdot \mathrm{K}^{-1}$

signal to noise ratio

diameter

radius

depth

thermal resistance

length

friction factor

Nusselt number

Reynolds number

Prandlt number

number of control parameters

Levels

density, kg. $\mathrm{m}^{-3}$

kinematic viscosity, $\mathrm{m}^{2} . \mathrm{S}^{-1}$

dynamic viscosity, N. $\mathrm{M}^{-2} \cdot \mathrm{s}^{-1}$

effectiveness

observed value ( $\mathrm{S} / \mathrm{N}$ ratio)

inner

outer

convective

pipe

air

soil

$\begin{array}{ll}\text { LB } & \text { lower is better } \\ \text { HB } & \text { higher is better }\end{array}$

$\mathrm{m}$ mean value

total value

error value 